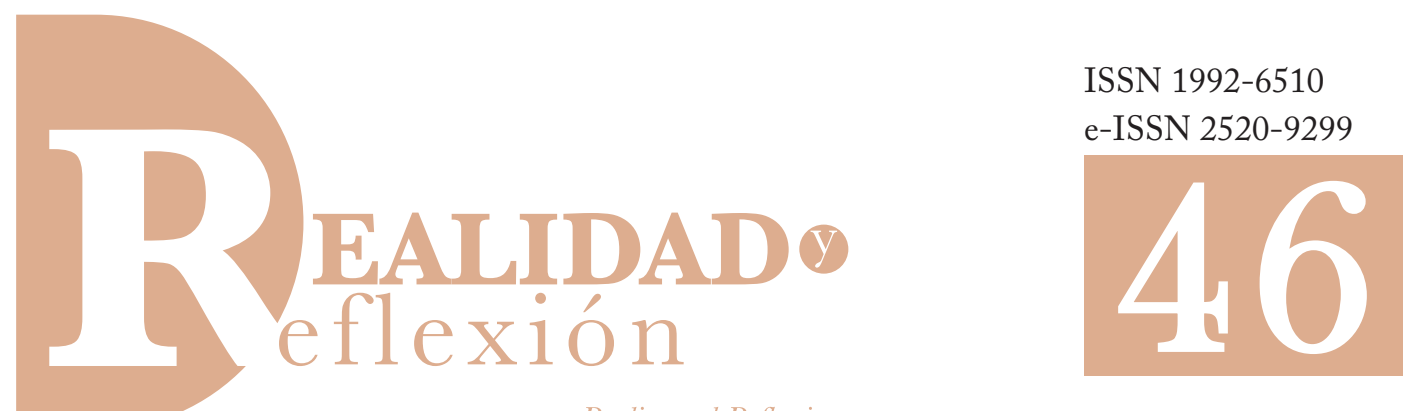

Reality and Reflection

Año 17, N 46, San Salvador, El Salvador, Centroamérica. Revista Semestral Julio-Diciembre 2017

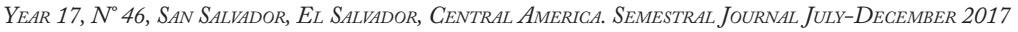

\title{
Aproximación al grabado de Camilo Minero
}

\section{Approach to Camilo Minero's artistic engraving}

\author{
Mauricio Linares-Aguilar ${ }^{1}$ \\ Doctorando en BBAA de la Universidad Complutense de Madrid \\ MFA, Fulbright College, Universidad de Arkansas, Estados Unidos \\ maulinar@ucm.es \\ Recibido: 9 de septiembre de 2017 \\ Aceptado: 1 de diciembre de 2017 \\ pág. 83 - 95 \\ DOI: http://dx.doi.org/10.5377/ryr.v0i46.5510
}




\section{Ponencia $^{2}$}

Camilo Minero (Zacatecoluca, 11 de noviembre de 1917- San Salvador, 6 de mayo de 2005) incursionó en diferentes disciplinas artísticas: el dibujo, la pintura de caballete, la pintura mural y el grabado. La presente conferencia pondera la relación entre el dibujo y el grabado que el maestro Minero desarrolló paralelamente a las otras disciplinas durante su trayectoria de setenta años.El objetivo dela misma es analizary describir algunos aspectos del proceso creativo implícito en su grabado y algunas de sus contribuciones al desarrollo del mismo en El Salvador. Yo he tomado como referencias sus grabados y dibujos, la mayoría presentes aquí en la Sala Nacional de Exposiciones, Salarrué con motivo de la exposición de dibujos y grabados Utopía. Camilo Minero, homenaje al artista por sus diez años de fallecimiento. También, algunos de los textos sobre su obra, los discursos publicados y más conocidos del artista, algunas referencias orales mencionadas en entrevistas, visitas guiadas $\mathrm{y}$ conversatorios que nos anteceden.

\section{La exposición ${ }^{3}$}

La idea curatorial de exponer las matrices junto a las impresiones denota un valioso interés pedagógico de la exhibición porque el espectador puede comprender mejor el proceso creativo y de producción de Minero en el grabado. Así,

2 Ponencia leída en la Sala Nacional Salarrué del Parque Cuscatlán en el marco de la exposición de grabado de don Camilo Minero, junio 2015.

3 Ponencia Utopía. Camilo Minero. Curaduría: Astrid Bahamond y Mayra Barraza. Sala Nacional de Exposiciones "Salarrué", Parque Cuscatlán, San Salvador, El Salvador, Centro América. 16 de abril-7 de junio de 2015.Catálogo disponible en línea en: https:// issuu.com/snesalarrue/docs/117cd_camilo_minero-utop_a evadiendo exhibir solamente las impresiones como en una exposición convencional, el público no especializado puede observar en las matrices la cantidad de trabajo implícito en las piezas y que no se puede percibir fácil y únicamente en las impresiones. Aquí se pone de manifiesto que el artista es precisamente quien elabora las matrices y que el proceso de impresión es una actividad que puede o no ser realizada por el mismo artista debido a las características mecánicas del mismo.

En el caso del maestro Minero, nosotros entendemos que él mismo imprimía sus piezas xilográficas. Por otro lado, aunque en esta exposición no contamos con serigrafías, el músico Godofredo Echeverría mencionó durante su intervención en el conversatorio anterior y con motivo de la muestra en esta sala que Minero consiguió durante su estancia en Nicaragua algunos recursos para implementar en su taller la técnica de la serigrafía y que además de producir su obra, el maestro tenía algunos discípulos dejando entrever que posiblemente le ayudaban con el estampado de sus ejemplares en serigrafía.

Nosotros debemos repetir que todas las piezas artísticas tienen un valor y mérito, todas de maneras diferentes y no unas menos que otras. No es difícil observar que el público salvadoreño en general mantiene un cierto recelo y subvaloración hacia el grabado porque asumen que se tratan de simples copias impresas de forma masiva y como tales carecen de valor en el mismo sentido que otros tipos de obras, como las pinturas por ejemplo que mantienen su unicidad. En el caso del grabado, la idea del original múltiple es esencial y válida porque presumimos que después de realizada una matriz, luego imprimimos una edición y las matrices quedan inservibles, gastadas 
o bien canceladas o destruidas por el artista y por lo tanto no habrán más ejemplares de la misma edición. Entonces, desapareciendo la utilidad de la matriz, las impresiones que se han realizado son las únicas evidencias del uso de esa matriz y las láminas impresas son las únicas existentes.

Cada vez que el artista transfiere la imagen de su matriz hacia el papel o cualquier otro soporte, la pieza resultante es diferente a las anteriores porque muestran variables algunas veces fuera de control del mismo artista y otras veces ejecutadas intencionadamente por el mismo. Aunque la imagen impresa resultante sea similar en una edición, las condiciones del estampado pueden variar físicamente. Por ejemplo, en la xilografía o grabado en madera que vemos aquí, la técnica exige que el entintado de la matriz sea realizada a mano. Por más que se intente mantener la misma cantidad homogénea de tinta esparcida, la mayoría de las veces con un rodillo, las intensidades tonales en toda la superficie nunca serán exactamente las mismas en una edición. Además, las matrices tienen un desgaste irreversible que hace que la imagen pierda detalles de impresión a impresión. Las matrices, especialmente las de madera, son difíciles de imprimir. Solo imaginemos la dificultad de que aparezcan exactamente las mismas vetas de la matriz original en una copia y también la fragilidad de la madera por la presión del tórculo.

\section{El dibujo como base del grabado}

La imagen creada por medio del dibujo es la génesis, el principio de la obra de Camilo Minero en general y por consiguiente también de su grabado. La obra en su totalidad manifiesta correspondencias de sus dibujos utilizados para varios medios, desde sus apuntes hasta los dibujos que pueden considerarse como piezas terminadas por sí mismas. Astrid Bahamond ya ha señalado que la fuerza creativa del maestro estriba en el dominio del dibujo. ${ }^{4}$ Nosotros también coincidimos con Ana María Minero, su hija, cuando afirma que "el dibujo es el hilo conductor de la obra global de Camilo Minero". 5

Aunque en el grabado existe la posibilidad de crear imágenes sin requerir del dibujo, este participa ineludiblemente en el grabado de Camilo Minero. Es decir que sus grabados nacen a partir de sus dibujos y de algunos recursos del dibujo técnico. Por esta razón, nosotros tenemos que recordar que el dibujo como disciplina se divide en varias modalidades y que en el grabado de Minero son detectables al menos dos de ellas: la primera que viene de sus habilidades personales como dibujante del modelo vivo y que desarrolla su expresión artística estableciendo los contenidos de sus obras y una segunda de carácter funcional y técnico que secunda y apoya la anterior. Por otro lado, la colección de dibujos del maestro merece un estudio más profundo y especializado porque es la fuente de información primaria y más pura de sus intereses como artista. En este sentido, nosotros podemos considerar al maestro Minero como un dibujante completo para su tiempo.

Como expresión artística, su dibujo sostiene su visión como artista y ser humano en los diversos

\footnotetext{
4 Astrid Bahamond, Camilo Minero, La Poesía del Testimonio, Museo de Arte de El Salvador, pág. 23.

5 Comentario oral durante el recorrido guiado de Giovanni Gil para la muestra Utopia, dibujos y grabados de Camilo Minero, Sala Nacional de Exposiciones Salarrué. 2015.
} 
contenidos en su obra. Nosotros podemos constatar estas aseveraciones desde sus propias palabras:

Soy un pintor representativo sacudido por profundas emociones y sentimientos.

He encontrado en el Hombre, en la Naturaleza y en nuestras tradiciones, los temasy modelos deinspiración para realizar mi obra; no puedo jamás abstraerme de la realidad que me circunda.

No vivo aislado de la sociedad, ni estoy parado sobre una roca en medio del océano. He buscado hacer arte sobre la vida cotidiana: la soledad, la muerte, el amor, el sufrimiento, el trabajo; lo inícuo (sic), y sobre todo, las inquietudes de nuestro pueblo son mis temas recurrentes. ${ }^{6}$

Más adelante el maestro agrega: "Soy un pintor figurativo, realista por excelencia, tal vez no soy modernista, pero tampoco me considero anticuado". 7 El maestro termina explicándonos que: "No es la doctrina la que hace a un artista, sino su personalidad. La honradez del artista conservará siempre el arte en todas sus manifestaciones". ${ }^{8}$

El artista se identifica a sí mismo reiteradamente como pintor en este discurso pronunciado para recibir el Premio Nacional de Cultura 1996. En esos años ser pintor era un rol reconocido y tal

6 Discurso de Camilo Minero en el día de entrega del Premio Nacional de Cultura en la rama de Artes Plásticas, 1996. Consejo Nacional para la Cultura y el Arte, CONCULTURA. Página 9.

7 Íbid.

8 Íbid. vez el más privilegiado entre las artes plásticas. No se mencionaba con frecuencia al artista visual o multidisciplinario como conocemos ahora al artista que desarrolla su obra en varias disciplinas de las artes visuales. Aunque en ese momento Minero hablaba como pintor, nosotros asumimos que él hablaba de su obra en general. Como ya sabemos, el artista mantuvo intereses similares en el mensaje, los temas e iconografía tanto en su obra pictórica de caballete $y$ mural como en su grabado. En este sentido y corroborado por sus experiencias y utilizando el lenguaje más actualizado, Camilo Minero ahora sería considerado dentro de esta terminología como un artista visual multidisciplinario.

Por otro lado, Roberto Galicia, presidente del Consejo Nacional para la Cultura y el Arte, CONCULTURA durante la administración del presidente Armando Calderón Sol, menciona que el premio es una consideración hacia la predominancia y mejor desarrollo expositivo de las artes plásticas y que por consenso el jurado decidió otorgárselo al maestro Camilo Minero por su trayectoria y aportes en el campo. ${ }^{9}$

\section{Primeros contactos con el grabado}

Nosotros sabemos que Minero ejecutaba sus grabados basándose en sus conocimientos adquiridos y su experiencia personal en el medio, pero al preguntarnos sobre cómo el maestro decide estudiar grabado, los antecedentes son limitados. El maestro Minero estudió dibujo y pintura en la Escuela de Artes Gráficas de San Salvador entre 1953 y 1957. Sin embargo, estos

\footnotetext{
9 Discurso de Roberto Galicia en el día de entrega del Premio Nacional de Cultura en la rama de Artes Plásticas, 1996. Consejo Nacional para la Cultura y el Arte, CONCULTURA. Página 7.
} 
datos no mencionan la iniciación del maestro Minero en el Grabado. Su familia sabe que el artista comenzó a trabajar como dibujante al trasladarse de Zacatecoluca a San Salvador. Así, Minero dibujaba a mano los carteles y anuncios de las películas y obras teatrales. Efectivamente, su familia también sabe que sus primeras experiencias en el grabado fueron en El Salvador. ${ }^{10}$

Sin embargo, no hay documentación consistente de un encuentro inicial o de una experiencia previa que nos indique o nos provea de suficientes pistas para comprender las razones para buscar posteriormente el estudio especializado en el grabado.

Algunos datos curiosos pueden dar algunas pautas para que el maestro Minero tuviera un interés especial en el grabado. El proceso en el grabado necesita no sólo de la atención del artista para seguir acuciosamente los pasos de la producción, sino también que el artista posea dotes espaciales. El proceso del grabado puede ser muy difícil de manejar para algunos artistas porque las imágenes deben invertirse tanto para acomodar paso a paso el diseño durante su ejecución como para verificarlo en el proceso de impresión. Por ejemplo, Ana María Minero, nos aclara que el artista era ambidiestro y que ejecutaba sus obras indistintamente con ambas manos y para dibujar utilizaba de preferencia la mano izquierda. También, el maestro escribía con ambas manos. Según estudios científicos sobre la percepción, las personas izquierdas tienen más desarrollados estos talentos espaciales porque utilizan más el lado derecho del cerebro. ${ }^{11}$ Un

10 Comentario de Ana María Minero en correo electrónico del 19 de mayo de 2015.

11 En el Manual de observación psicomotriz: significación neurológica de los factores psicomotores de Da Fonseca y Trigo Aza, páginas 84-86. estudio grafológico de su escritura certificaría las dotes del maestro en este sentido.

Nosotros sostenemos la hipótesis de que Minero fue enviado a México a estudiar grabado, primero por su curiosidad y necesidad de experimentación artística y segundo por la necesidad que había de capacitar al futuro personal docente de la Escuela de Artes Gráficas. Según los datos que tenemos, el artista egresa de esa escuela en 1957, año de su partida hacia México y además, Mario Castrillo señala que en 1960 a su regreso de México, el maestro trabajó como docente de grabado en esa misma extinta Escuela. ${ }^{12}$ Hasta este momento de la investigación, nosotros sabemos por medio del maestro Armando Solís (El Salvador, 1940) que en los años cincuenta del siglo $\mathrm{XX}$, cuando la Escuela era dirigida por Luis Alfredo Cáceres Madrid (E1 Salvador, 1908-1959) había un taller de grabado litográfico, pero que no era utilizado con fines estrictamente pedagógicos sino más bien comerciales, pues este aportaba a la escuela algún sostenimiento. Solís recalcó que el grabado en ese entonces se veía más con fines comerciales y artesanales que artísticos. ${ }^{13}$ Por otro lado, José Roberto Cea (El Salvador, 1939) menciona entre las asignaturas relacionadas al grabado en la Escuela de Artes Gráficas: Dibujo Lineal, Dibujo Natural, Pintura; Fotograbado, Fototipia, Dibujo a Líneas, Tricromía, Cuatricromía; Fotografía, Ampliaciones; Litografía, Tipolitografía, Fotolitografía; Tipografía, Dibujo Tipográfico, Comparación, Factura de Libros, Revistas,

12 Mario Castrillo, datos cronológicos de Camilo Minero referidos por Astrid Bahamond en el catálogo Camilo Minero: la Poesía del Testimonio. Museo de Arte de El Salvador, MARTE.

13 Respuestas de Armando Solís al contestar mi pregunta durante el conversatorio sobre la vida y obra de Camilo Minero: si existía un taller de grabado en la extinta Escuela de Artes Gráficas fundada por Carlos Alberto Imery. 
Conocimiento y Manejo de Prensas, Linotipos, Encuadernación; Caligrafía, Dactilografía, Taquigrafía; Nociones de Telegrafía y Telefonía, Radiotelegrafía; Modelación y Escultura; divididas estas materias en nueve secciones a partir de una sección preliminar. ${ }^{14}$ Sin embargo, no sabemos cuáles de todas estas materias cursaría el maestro para determinar si en efecto además de las materias de la especialidad en dibujo y pintura, en algún momento tomó materias relacionadas al grabado o fungió como aprendiz o ayudante del taller que existió en esa escuela.

Ante el vacío de un registro que documente y relacione las asignaturas y el taller de grabado de la Escuela de Artes Gráficas con el maestro Minero durante su etapa estudiantil, nosotros podríamos conjeturar que el maestro conoció el taller y observó lo que ahí se hacía, y que probablemente él tuvo o no tuvo algún adiestramiento en el mismo. Otra hipótesis adicional sería que el maestro José Mejía Vides (E1 Salvador, 1903-1993), quien no sólo fue docente de la misma escuela, sino que también él mismo ya había conocido el grabado xilográfico en México, podría haber apoyado a Minero desde su cargo, como jefe del departamento de Artes Plásticas en la Dirección General de Bellas Artes, para que él se fuera a México a estudiar grabado. En todo caso, estas dos hipótesis serían importantes de documentar para comprender la iniciación del maestro Minero en el grabado.

Así, Camilo Minero estudió grabado en el Taller de la Gráfica Popular en México Distrito Federal desde 1957 hasta 1960 bajo los auspicios

14 Cea,J. R.(1986). De la pintura en El Salvador:panorama histórico crítico. San Salvador: Editorial Universitaria, Universidad de El Salvador. del gobierno de El Salvador. ${ }^{15}$ Como ya sabemos, el artista trabajó como docente de grabado en la Escuela de Artes Gráficas en 1960 al regresar al país y además en la Universidad Nacional de El Salvador entre 1993 y $1995 .{ }^{16}$

\section{Del dibujo al grabado}

Minero trabajó su grabado en una secuencia de pasos. Primero, el maestro utilizó el dibujo como manifestación visual de su idea, de su motivo o tema para acomodarlo de varias maneras en sus obras. La mayoría de veces como un estudio preciso sobre papel que sufriría algunos cambios en beneficio de la composición final y otras en adaptaciones de escala para los diferentes propósitos. Las más obvias son las extracciones de la figura y la disposición de un fondo que no siempre existe en el mismo dibujo. También, nosotros notamos por ejemplo, las diferencias de tamaño de un diseño similar en una pintura y una matriz de grabado. Las matrices utilizadas en sus grabados fueron más pequeñas que sus pinturas y estas matrices en su mayoría condicionan su tamaño a las dimensiones de su tórculo personal. Según Ana María Minero, en el caso de sus impresiones de mayor tamaño el artista las acondicionó modularmente para imprimirlas utilizando el mismo tórculo. El artista perfeccionó esta técnica al grado que los cortes o divisiones del entintado no se notasen. ${ }^{17}$

\footnotetext{
15 Mario Castrillo, datos cronológicos de Camilo Minero referidos por Astrid Bahamond en el catálogo Camilo Minero: la Poesía del Testimonio. Museo de Arte de El Salvador, MARTE.
}

16 Ibíd.

17 Comentario de Ana María Minero en correo electrónico del 19 de mayo de 2015. 
El dibujo en el grabado de Minero expone características formales que han concluido en un lenguaje personal. Astrid Bahamond describe el tratamiento de la línea del maestro Minero como preciso y con direccionalidad. ${ }^{18}$ Esta aseveración puede extenderse de igual forma al tratamiento de las incisiones en las matrices de su grabado en xilografía que son una manera de trazar pero con el propósito de hundir cada línea en el soporte y que por razones técnicas de la resistencia de la madera, las incisiones no son tan fluidas como en otros medios.

Si bien es cierto que el dibujo es el fundamento de la obra de Camilo Minero, el dibujo utilizado en el grabado presenta algunas diferencias respecto a los dibujos preparatorios y el dibujo presente en su obra pictórica. La transferencia del dibujo hacia la matriz y el trabajo de calado, recortado e incisión en los retratos puede darnos algunas pistas sobre esta variables. Por ejemplo, el uso del contorno es más pronunciado y zonifica con intensidad las áreas que determinan la relación figura y fondo. Aquí, nosotros necesitamos recordar que la separación de la figura con el fondo es un formulismo recurrente en el arte occidental dotando al personaje representado un mayor interés y luego de una escenografía complementaria para explicar el contexto del mismo.

El grabado fue para Camilo Minero una disciplina importante en su carrera. La cantidad de obras realizadas en grabado deja constancia no sólo de su interés en el mismo, sino también del largo tiempo invertido en la creación de las obras. El dibujo que fundamenta su pintura de caballete y mural extiende su conectividad hacia

18 Bahamond, A. Camilo Minero, La Poesía del Testimonio. Museo de Arte de E1 Salvador, pág. 23. el grabado. Por ejemplo, en muchos casos los dibujos que han sido utilizados como referencias para una pintura, también ha sido utilizado para generar una matriz de grabado. Algunos diseños como el del Carrusel, que también es uno de los temas de sus pinturas más difundidas de caballete, también está presente aquí en esta exhibición como grabado. Estas diferentes

variaciones compositivas generan un cuerpo de obras que podrían ser consideradas como una serie temática. No obstante, las características de cada medio establecen otras diferencias, así como también algunas alteraciones en los ángulos de la perspectiva, la composición y en los tamaños de los formatos utilizados. Adicionalmente, nosotros podemos ver aquí en la Sala Nacional otros dibujos que modificados en su escala y alterados en su diseño inicial, han sido trazados en las matrices, a la inversa $y$ las impresiones correspondientes a partir de las mismas. Por ejemplo, en la obra de $L a$ Ignorancia, tenemos un dibujo preliminar de su representación con una joven y luego otro dibujo definitivo que representa una mujer de avanzada edad. Los detalles de la iconografía cambian y el fondo también es diferente entre los dibujos y el diseño de la matriz. En este sentido, nos resulta sumamente claro que el artista no siempre se quedaba con el dibujo inicial que realizaba, sino que su tema y su diseño evolucionaba hasta llegar a la matriz cobrando más fuerza.

En el grabado de Minero el dibujo transferido dirige el trabajo laborioso de las incisiones. Así, el trazo inicial puede modificarse ligeramente por las decisiones del artista en el proceso de ejecución. La proximidad y yuxtaposición del entramado van generando planos y sensaciones 
de volumen y profundidad además de una escala de matices reducida y que muchas veces es anulada por la aparición del alto contraste. En este sentido, en su grabado hay una competencia entre estos tratamientos y otros que enfatizan el medio aplanado propio del grabado xilográfico. Sin embargo, en el caso de Minero estas integraciones peculiares y manejos técnicos han sido realizados con pericia al ejecutar sus matrices.

Las figuras, en la mayoría de los casos, poseen una especie de halo alrededor en sus grabados, con excepción del retrato de Alberto Masferrer, estos elementos no aparecen en sus dibujos preparatorios. Como solución formal, esta sensación se debe por la insistencia de que la figura destaque del fondo mismo o bien que la figura delimite una zona de color. Así, en el retrato de Alberto Masferrer las matrices ya separadas por los colores negro, azul o rojo definen este halo, las zonas delimitadas para su impresión. La representación de este halo sugiere la necesidad de enaltecer a los personajes al otorgarles un aura, que sería en todo caso un aditamento simbólico para la caracterización de sus personajes. Así, la luz deviene símbolo de la iluminación y del bien. ${ }^{19}$

Camilo Minero fue un artista que utilizaba los recursos técnicos de la época. A pesar de que la xilografía es una técnica de grabado muy antigua, el artista supo incorporar nuevos elementos en el proceso de elaboración de sus grabados xilográficos. Probablemente por estas cavilaciones, en su discurso al recibir el Premio Nacional de Cultura, Minero nos hace dudar si es

19 Cirlot, J. E. (1997). Luz, Diccionario de Símbolos. Página 141. o no modernista y al mismo tiempo considerarse que no es un artista anticuado. ${ }^{20}$ Nosotros creemos que es pertinente recordar estos datos aquí porque el maestro además de sostener altos ideales humanistas muy propios del modernismo, él también demuestra una clara convicción modernista de utilizar los recursos y la tecnología al alcance. En nuestro medio todavía persiste una especie de recelo, burla y hasta indignación de parte de algunos artistas porque otros artistas utilizan estos instrumentos más actuales como la computadora, el proyector de opacos y el cañón utilizado en las presentaciones en los auditorios. El punto en discusión es que el artista debe dibujar directamente y dejar evidencia de su habilidad ya sea natural o adquirida para que le creamos que maneja el oficio. Ellos tienen algo de razón porque todos estos artilugios permiten elaborar imágenes sin ser dibujantes prestándose a ciertas charlatanerías y usos indebidos. Sin embargo, tampoco es válido desaprovechar los recursos que se tienen en la actualidad porque nosotros estaríamos relegados del contexto global que maneja estos medios no sólo con prestancia sino con increíble naturalidad y franqueza. En este sentido, Camilo Minero ha dejado evidencia que además de ser un dibujante probo, también utilizó los recursos técnicos que tuvo a su alcance en su tiempo sin sostener esta actitud parcializada hacia las dotes innatas o adquiridas que mencioné anteriormente.

El dibujo técnico fue también utilizado por Minero. Además de las cualidades expresivas, el dibujo en su grabado tiene una valoración funcional en el proceso de elaboración de

20 Discurso de Camilo Minero en el día de entrega del Premio Nacional de Cultura en la rama de Artes Plásticas, 1996. Consejo Nacional para la Cultura y el Arte, CONCULTURA. 
las matrices. Así, el recurso de la retícula es utilizado de la misma manera que los autores clásicos más tradicionales que mediante una serie de operaciones aritméticas básicas establece cuadrantes pautados y sectorizados para reducir o ampliar las imágenes completas sobre el soporte. Por ejemplo, la retícula le sirvió al maestro Minero para ampliar y trasladar sus dibujos iniciales, bocetos o estudios fotográficos al soporte incluyendo las matrices, cuyas dimensiones varían de acuerdo a cada obra en particular.

El seccionado que el maestro Minero solía hacer en varias de sus obras es una derivación del recurso de la retícula. Así, el maestro no solo le interesó transferir el dibujo sino que también el decidió transferir la retícula de forma íntegra o alterada en algunas partes según sus propias determinaciones. Como sabemos, este sistema de la retícula utiliza figuras geométricas simples como el cuadrado, el rectángulo y las diagonales que dividen y centran el plano. El maestro Minero fue personalizando su propio sistema de ampliación y también logró transparentar esta parte del proceso al incluirlo con determinación en su obra. En casos como el de La Ignorancia el diseño reticular está transferido e incorporado como parte del diseño total. La línea curva que recorre la parte superior del dibujo recuerda uno de los tantos procedimientos que contribuye a modificar la apariencia del diseño. En esta secuencia de bocetos el recurso parece auxiliar el ensanchamiento de la figura. En otros diseños puede notarse la extracción de algunas y la suma de otras líneas del reticulado, en especial líneas diagonales. Al agregar estas proyecciones que entretejen una estructura geométrica sobre sus dibujos, las obras, tanto los dibujos, los grabados como sus pinturas, adquirieron un aspecto más dinámico e inquietante. En este mismo sentido, el artista destacó las secciones generadas por esta estructura lineal con tratamientos texturales y tonales de cierta independencia y que le adjudicarían sensaciones diversas: a veces como un vitral y otras como piezas de un rompecabezas. También, estas resoluciones compositivas causan diferentes asociaciones a los recursos geométricos que fragmentan las figuras en el espacio utilizados por los artistas de las vanguardias de principios del siglo XX, pero sin llegar a establecer una conexión particular.

La vitrina de la sala didáctica de la exposición Utopia, dibujos y grabados en la Sala Nacional de Exposiciones muestra varias fotografías de sus modelos. Algunas de ellas conservan las retículas a lápiz que el artista trazó para ampliar las imágenes de los mismos. Este recurso empleado por Minero nos informa que además de su habilidad para dibujar del natural, el maestro se valía adicionalmente de otros recursos que tenía al alcance. Por otro lado, pese a que el maestro Minero utilizó el mismo recurso de la retícula, y si bien es cierto que es difícil saber con exactitud las fechas de estos trabajos, nosotros podemos detectar la influencia de grabado mexicano en algunos de los retratos de estos intelectuales porque la composición y ejecución semeja la audacia y el carácter estilístico de los maestros del grabado mexicano. Otros tienen una composición más apegada al canon de representación del retrato histórico y tienen un tratamiento más meticuloso y sereno. Las referencias fotográficas son más evidentes en estos últimos casos. En una revisión muy general de la historia del arte vale la pena recordar que la fotografía cambió por completo el curso de las artes visuales desde su advenimiento a finales del siglo XIX. El recurso 
fue rechazado por algunos artistas y asimilado por otros. También vale la pena recordar que la cámara obscura, que es el origen de la cámara fotográfica y que se dice hasta el momento que fue creada por los árabes en el siglo X, la utilizó Leonardo da Vinci, Caravaggio y Johannes Vermmer para mencionar algunos.

El grabado de Camilo Minero comparte la sencillez del dibujo utilizado en sus pinturas murales y de caballete. Aunque sus dibujos también son los recursos primarios para sus grabados, estos evidencian una fortaleza particular por el giro y sustitución del color al blanco y negro o bien cuando persiguen una selección limitada de colores convirtiéndose en una interpretación más sintética y plana que las usuales en sus pinturas. Los grabados en su gran mayoría son diseños que están impresos en negro sobre el color del papel que aporta un segundo color para el contraste. Así, cada imagen proviene de una sola matriz. En casos particulares hay dos matrices que definen la separación del color y las impresiones resultantes suman el color del papel. Ciertamente este lenguaje formal del blanco y negro que impera en la mayoría de sus grabados nos aleja de una inmediata asociación con su pintura.

Aunque en varios grabados utiliza el color amarillo como parte de su limitada selección de colores, los grabados se alejan de una inmediata asociación de su pintura que cromáticamente se recrea a partir de una paleta cálida que también parte del amarillo. Así, en algunos de sus paisajes donde utiliza este color y aunado al tratamiento arremolinado de los trazos del dibujo y las incisiones en sus matrices recuerdan los paisajes de Vincent Van Gogh. Además, en sus grabados podemos advertir sugerencias de las composiciones basadas en triangulaciones o divisiones del plano por medio de diagonales extendidas y sobrepuestas que separan el color de los diseños y que aparecerán también en sus pinturas. Por ejemplo, en sus paisajes, el tratamiento de planos divididos en los cerros y que representan los sembradíos ya advierten estas cualidades.

En otros casos excepcionales algunas impresiones sugieren la técnica de la matriz perdida que modifica paulatinamente el diseño y el color. Por ejemplo, en la obra Covachas de 1990 las formas orgánicas que sugieren celajes concéntricos en el fondo del paisaje parecen haber sido impresos utilizando esta técnica que conjuga la impresión de un color en un número determinado de láminas para luego intervenir la matriz haciendo incisiones que dejarán en evidencia el color anterior en ciertas áreas y sobrepondrán otro color sobre el ya existente a veces bloqueando grandes zonas del color anterior. En el efecto final impreso pareciera que se han utilizado varias matrices adicionales por color, cuando en realidad es la misma pero alterada.

En esta exposición de Camilo Minero podemos observar que no hay matrices canceladas. Es decir, inhabilitadas intencionalmente por el artista para no proliferar más su uso y así evitar la impresión de otras copias. Esta cancelación es el trazo inciso de una gran equis cruzando toda la matriz o bien alterándola con el texto cancelado. Aunque nosotros lo ignoramos, desde el momento que el maestro no canceló sus matrices al parecer y probablemente, muchas de ellas todavía estuvieron sujetas a imprimirse por el artista o bien a realizar otra edición diferente 
a partir de ellas. También, otra posibilidad que cabe mencionar es que el anhelo de conservación de las matrices del grabador puede impedir su cancelación o su total destrucción.

En este mismo sentido, nosotros podemos mantener la duda sobre los tirajes ejecutados por el artista y su control de edición. En muchos casos hay una numeración clara $\mathrm{y}$ precisa de las láminas. Sin embargo, en otros casos existen láminas que únicamente están firmadas, pero no están numeradas como si se tratase de una edición abierta o sin número. En casos distintos, las láminas impresas no tienen firma o bien anotan su identificación en la base como quien escribe los datos de una cédula informativa. Adicionalmente, otras matrices tienen la firma de Camilo Minero incisa e incorporada en el diseño mismo. Es decir, la firma también está considerada para ser impresa desde que se ejecutó la matriz. Este criterio, como bien lo señaló Giovanni Gil, fue un recurso utilizado por los grabadores en los siglos anteriores al siglo XIX cuando el grabado era más utilizado como recurso de ilustración y no había un interés claro del artista ni del público en el tema de derechos de autor. Nosotros creemos que Don Camilo quería que estas matrices fuesen impresas sin numeración como en aquellos tiempos que no había un control estricto sobre el número de ejemplares impresos a partir de una misma matriz sino hasta que la misma matriz cediera por completo. En general, es notorio, y al igual que muchos de sus contemporáneos, que este control de las impresiones de grabado y de las ediciones no fue atendido con rigor y probablemente al maestro Minero no le importó tanto como las convenciones y tratados internacionales en el tema lo explican desde los años 60, sino que él estuvo más enfocado en la rápida difusión de sus impresiones.

El recurso visual del contraste, tan ligado a la iconografía revolucionaria del siglo $\mathrm{XX}$, es en efecto un factor determinante que liga el pensamiento y la intencionalidad expresiva de Minero en sus grabados. El mensaje canalizado a través de esta práctica visual le ayuda a conectarse con los movimientos visuales revolucionarios mexicanos y de otras latitudes precisamente porque ellos también utilizaron el contraste y el alto contraste, como medio de difusión de sus ideas revolucionarias y hasta propagandísticas. Por ejemplo, esta solución formal es más evidente en el grabado de la sección de los torturados y otros grabados donde alude al sufrimiento de la guerra y la deshumanización.

La economía del diseño general se ve enriquecido, a veces profusamente, por las texturas logradas a base del entramado lineal de controladas incisiones realizado por el artista. Si ponemos atención a las matrices podemos observar que el trabajo de incisión es acucioso, detallado y hasta trabajado en exceso. Tal es el caso que mucho de ese trabajo de incisiones de diverso grosor no queda registrado en las impresiones debido a los niveles de profundidad logrados en la matriz y que no siempre estarían alcanzando el nivel adecuado para transferirse en el papel por medio de la presión en el tórculo o bien por el frotado manual de un baren. Una impresión en seco en un papel grueso dejaría la evidencia en relieve de todo este trabajo magistral que no logramos percibir en una impresión con tinta.

La textura y las vetas del soporte de madera de la matriz muchas veces son integradas a 
la sinuosidad de las incisiones trazadas por el artista. En otras matrices e impresiones podemos ver que es evidente que el artista ejecutó su diseño obviando la continuidad de las vetas de la madera a propósito y en otras acentúa su diferencia al realzar las vetas de la matriz por encima del diseño. Por ejemplo, en Paisaje Rural de 1970, podemos apreciar que el diseño y sus incisiones no continúan con el ritmo de las vetas de la matriz, sino que el artista las integra pero acentuando su yuxtaposición generando luces y otros tonos colaterales a las vetas.

El maestro Minero utilizó varias clases de maderas preciosas para matrices pequeñas. También, en el conjunto existen matrices de madera comprimida o plywood. Giovanni Gil en su recorrido guiado también señaló el criterio ecológico de escoger este tipo de panel para no utilizar estas maderas preciosas que usualmente y con anterioridad a las observaciones y controles éticos y ecológicos eran no sólo bien vistos sino que casi exigidos como soporte por su resistencia a la presión, al tiraje y al tiempo.

Para terminar esta conferencia, con motivo de la exposición Utopía. Camilo Minero que rinde un homenaje a los diez años de su fallecimiento, tenemos aquí en la Sala Nacional de Exposiciones "Salarrué" del Parque Cuscatlán de San Salvador una parte importante del legado de Camilo Minero en el dibujo y en el grabado. El dibujo es la base de su grabado al igual que en todas las disciplinas que el maestro cultivó. De igual forma su grabado es coherente con sus principios estéticos e ideológicos. Camilo Minero retoma del realismo social las bases para construir su lenguaje personal que ahora podemos distinguir por su concreta sencillez figurativa y por su determinación representativa del contexto popular y cotidiano. El maestro Minero demostró no sólo un especial respeto a la tradición de las técnicas del grabado como la xilografía, sino también un interés experimental por otras técnicas del grabado como la serigrafía. Aunque el cuido de sus ediciones no fue atendido plenamente por el maestro Minero, la difusión inmediata de su grabado fue al parecer su mayor interés.

\section{Bibliografía}

Bahamond, A. (2005). Camilo Minero: la poesía del testimonio. San Salvador: Asociación Museo de Arte Moderno de El Salvador.

Bahamond, A. (2015). Utopía, dibujos y grabados. Texto curatorial de la exhibición de Camilo Minero. Evento organizado por la Sala Nacional de Exposiciones Salarrué. San Salvador.

Castrillo Z., M. (2004). Camilo Minero, Hombre de Barro y Luz. E1 Salvador: Fundación Paiz Concultura.

Castrillo Z., M., Mata, I.; y Solís, A. 2009. Camilo Minero: un homenaje a su obra. San Salvador: Ministerio de Relaciones Exteriores.

Castrillo Z., M., Echeverría, G. y Solís, A. (Mayo de 2015). Historias compartidas: Amigos de Camilo Minero. Llevado a cabo en la Sala Nacional de Exposiciones de El Salvador Salarrué, en San Salvador. Disponible en: https://soundcloud.com/snesound/ conversatorio-historias-compartidasamigos-de-camilomp3 
Cea, J. (1986). De la pintura en El Salvador: panorama bistórico crítico. San Salvador: Editorial Universitaria, Universidad de El Salvador.

Cirlot, J. (1997). Diccionario de simbolos. Madrid: Ediciones Siruela.

Cornejo,J.(1996). Camilo Minero, pintor delpueblo. San Salvador: Ediciones Casa de Zacate.

Minero, C. (1996). Discurso Premio Nacional de Cultura 1996. Leído en el evento de entrega del Premio otorgado por el Consejo Nacional para la Cultura y el Arte de El Salvador, CONCULTURA a Camilo Minero. San Salvador.
Solís, A. (1998). Camilo Minero:La orilla roja del girasol (biografia). San Salvador: Editorial Génesis.

Vítor da, F. y Trigo Aza, E. (1998). Manual de observación psicomotriz: significación psiconeurológica de los factores psicomotores. Barcelona: Inde Publicaciones. 